\title{
Gambaran temporomandibular disorders pada lansia di kecamatan wanea
}

\author{
${ }^{1}$ Johannis Gabrila \\ ${ }^{2}$ Lydia Tendean \\ ${ }^{3}$ Kustina Zuliari \\ ${ }^{1}$ Kandidat Skripsi Program Studi Pendidikan Dokter Gigi Fakultas Kedokteran \\ ${ }^{2}$ Bagian Biologi Fakultas Kedokteran \\ ${ }^{3}$ Program Studi Pendidikan Dokter Gigi Fakutas Kedokteran \\ Universitas Sam Ratulangi Manado \\ Email: gabyjohannis@yahoo.co.id
}

\begin{abstract}
Abstarct: Elderly was the final phase of the development of human life. The elderly will experience a reduction of posterior or anterior teeth, degeneration, thinning of the oral mucosa, hyposalivation, decreased activity and muscle mass, setbacks of many body functions including temporomandibular joint (TMJ) function. Arthritis and osteoporosis that occur in TMJ due to excessive load as well as tooth loss lead to temporomandibular disorders (TMD). Elderly who has TMD will experience discomfort in eating and drinking. This study aimed to obtain the description of TMD among the elderly at Wanea district. This was a descriptive study with a cross sectional design conducted in June 2016. Samples were obtained by using purposive sampling. The elderly were interviewed by using the Fonseca's questionnaire and were checked for clicking sound and teeth loss. The results showed that of 98 respondents, there were 54 elderly with mild TMD, 12 elderly with moderate TMD, and 5 elderly with severe TMD; 28 elderly had no TMD. Clicking sound was found in 70 elderly, partial tooth loss in 78 ederly, and whole tooth loss in 20 ederly. Conclusion: Most elderly in Wanea had TMD. The most frequent that had TMD was age 60-70 years old and females. The most common classification of TMD was mild TMD.
\end{abstract}

Keywords: elderly, temporomandibular disorders.

\begin{abstract}
Abstrak: Lanjut usia (Lansia) merupakan tahap akhir perkembangan dari kehidupan manusia. Lansia umumnya mengalami pengurangan jumlah gigi geligi posterior maupun anterior, terjadi degenerasi, penipisan mukosa oral, hiposalivasi, penurunan aktivitas dan massa otot, serta terjadi kemunduran banyak fungsi tubuh termasuk fungsi sendi temporomandibular (TMJ). Artritis dan osteoporosis yang dapat terjadi pada TMJ akibat beban berlebihan serta kehilangan gigi pada lansia mengakibatkan terjadinya temporomandibular disorders (TMD). Lansia yang mengalami TMD akan mengalami ketidaknyamanan dalam hal makan dan minum. Penelitian ini bertujuan untuk mengetahui gambaran TMD pada lansia di Kecamatan Wanea dan dilaksanakan pada bulan Juni 2016. Jenis penelitian ialah deskriptif dengan desain potong lintang. Pengambilan sampel menggunakan purposive sampling. Pada penelitian ini dilakukan wawancara pada lansia menggunakan Fonseca's Questionnaire, serta pemeriksaan bunyi clicking dan pemeriksaan kehilangan gigi. Hasil penelitian mendapatkan dari 98 responden, 54 lansia mengalami TMD ringan, 12 lansia TMD sedang, 5 lansia TMD berat; 28 lansia tanpa TMD. Bunyi clicking terdapat pada 70 lansia, kehilangan gigi sebagian sebanyak 78 lansia, dan kehilangan gigi seluruhnya sebanyak 20 lansia. Simpulan: Sebagian besar lansia di Kecamatan Wanea mengalami TMD. Yang tersering ditemukan ialah kelompok usia 60-70 tahun, jenis kelamin perempuan dan klasifikasi TMD ringan.
\end{abstract}

Kata kunci: lansia, temporomandibular disorders 
Jumlah lansia di Indonesia setiap tahunnya meningkat dengan usia harapan hidup yang juga semakin meningkat dari tahun ke tahun. Data Komnas Lansia mencatat pada tahun 2007 persentase lansia di Indonesia yaitu $7,18 \%$ dari total populasi penduduk. Komnas lansia memperkirakan pada tahun 2020 persentase lansia mencapai $11 \%$ jiwa, namun pada tahun 2010 persentase lansia di Indonesia telah mencapai $22 \%$ jiwa. Hal ini menunjukkan adanya peningkatan penduduk lebih besar dari yang diperkirakan. Komnas Lansia juga memperkirakan pada tahun 2025 persentase lansia di Indonesia mencapai $32 \%$ dari total populasi penduduk. Pada lansia terjadi penurunan kemampuan pikir dan fisik yang diakibatkan karena proses menua. ${ }^{1}$

Menua merupakan suatu proses menghilangnya secara perlahan-lahan kemampuan jaringan untuk memperbaiki diri dan mempertahankan fungsi normal sehingga lebih rentan terhadap infeksi. Walaupun menua merupakan keadaan alami dalam kehidupan manusia, para lansia tetap membutuhkan upaya pemeliharaan serta peningkatan kesehatan dalam rangka mencapai masa tua yang sehat, bahagia, berdaya guna, dan produktif. ${ }^{2}$

Proses menua pada lansia umumnya berupa pengurangan jumlah gigi-geligi posterior dan anterior, terjadi degenerasi, penipisan mukosa, hiposalivasi, penurunan aktivitas dan massa otot, serta terjadi kemunduran pada banyak fungsi tubuh; salah satu di antaranya yaitu fungsi sendi temporomandibular (TMJ) untuk mengunyah. TMJ dapat mengalami artritis dan osteoporosis akibat beban berlebihan serta adanya faktor kehilangan gigi pada lansia yang berakibat kelainan temporomandibular atau temporomandibular disorders (TMD). ${ }^{3}$

Temporomandibular disorders merupakan kumpulan gejala klinis yang melibatkan otot pengunyahan di daerah orofacial, sendi atau keduanya. Gejala yang paling sering ditemukan pada TMD ialah suara pada saat sendi bergerak. Kehilangan gigi di bagian posterior diindikasikan sebagai penyebab TMD oleh karena kelainan oklusal yang menyebabkan ganguan fungsi sendi. ${ }^{4}$

Lansia memerlukan nutrisi yang adekuat untuk mendukung dan mempertahankan kesehatan. Lansia dengan TMD akan mengalami berkurangnya asupan makanan yang menjadi sumber gizi yang sangat diperlukan bagi tubuh oleh karena ketidaknyamanan dalam hal makan dan minum. ${ }^{4-5}$ Penelitian Himawan et al. ${ }^{6}$ pada 50 sampel dengan rentang usia dari 60-91 tahun melaporkan $68 \%$ lansia yang mempunyai gejala TMD.

\section{BAHAN DAN METODE PENELITIAN}

Jenis penelitian ini ialah deskriptifobservasional dengan desain potong lintang. Penelitian dilaksanakan di Kecamatan Wanea pada bulan Juni 2016. Populasi penelitian ialah semua lansia yang berada di Kecamatan Wanea berjumlah 4628 jiwa. Besar sampel dihitung menggunakan rumus Slovin dan didapatkan sebanyak 98 sampel. Responden diberikan informed consent kemudian dilakukan pengukuran TMD menggunakan Fonseca's Questionnaire, pemeriksaan bunyi clicking menggunakan metode auskultasi, dan pemeriksaan kehilangan gigi menggunakan kaca mulut. Data diolah dan disajikan dalam bentuk tabel distribusi frekuensi.

\section{HASIL PENELITIAN}

Tabel 1 dam 2 memperlihatkan karakteristik responden berdasarkan jenis kelamin dan usia.

Tabel 1. Distribusi responden berdasarkan jenis kelamin

\begin{tabular}{ccc}
\hline Jenis kelamin & n & \% \\
\hline L & 35 & 36 \\
P & 63 & 64 \\
Total & 98 & 100 \\
\hline
\end{tabular}

Tabel 2. Distribusi responden berdasarkan usia

\begin{tabular}{ccc}
\hline Usia (Tahun) & n & \% \\
\hline $60-70$ & 55 & 56 \\
$71-80$ & 30 & 31 \\
$81-90$ & 12 & 12 \\
$>91$ & 1 & 1 \\
Total & 98 & 100 \\
\hline
\end{tabular}


Jurnal e-GiGi (eG), Volume 4 Nomor 2, Juli-Desember 2016

Tabel 3. Distribusi TMD pada lansia di Kecamatan Wanea

\begin{tabular}{ccc}
\hline Klasifikasi TMD & n & \% \\
\hline Tanpa TMD & 28 & 29 \\
TMD ringan & 53 & 54 \\
TMD sedang & 12 & 12 \\
TMD berat & 5 & 5 \\
Total & 98 & 100 \\
\hline
\end{tabular}

Tabel 4. Distribusi TMD pada lansia berdasarkan jenis kelamin

\begin{tabular}{|c|c|c|c|c|c|c|c|c|c|c|}
\hline \multirow{2}{*}{ Jenis kelamin } & \multicolumn{2}{|c|}{ Tanpa TMD } & \multicolumn{2}{|c|}{ TMD ringan } & \multicolumn{2}{|c|}{ TMD sedang } & \multicolumn{2}{|c|}{ TMD berat } & \multicolumn{2}{|c|}{ Total } \\
\hline & $n$ & $\%$ & $\mathrm{n}$ & $\%$ & $n$ & $\%$ & $\mathrm{n}$ & $\%$ & $\mathrm{n}$ & $\%$ \\
\hline $\mathrm{L}$ & 10 & 10 & 16 & 16 & 6 & 6 & 3 & 3 & 35 & 36 \\
\hline $\mathrm{P}$ & 18 & 19 & 37 & 38 & 6 & 6 & 2 & 2 & 63 & 64 \\
\hline Total & 28 & 29 & 53 & 54 & 12 & 12 & 5 & 5 & 98 & 100 \\
\hline
\end{tabular}

Tabel 5. Distribusi TMD pada lansia berdasarkan usia

\begin{tabular}{ccccccccccc}
\hline \multirow{2}{*}{ Usia (tahun) } & \multicolumn{2}{c}{ Tidak ada } & \multicolumn{2}{c}{ TMD ringan } & \multicolumn{2}{c}{ TMD sedang } & \multicolumn{2}{c}{ TMD berat } & \multicolumn{2}{c}{ Total } \\
\cline { 2 - 12 } & $\mathrm{n}$ & $\%$ & $\mathrm{n}$ & $\%$ & $\mathrm{n}$ & $\%$ & $\mathrm{n}$ & $\%$ & $\mathrm{n}$ & $\%$ \\
\hline $60-70$ & 17 & 17 & 32 & 33 & 3 & 3 & 3 & 3 & 55 & 56 \\
$71-80$ & 8 & 8 & 15 & 15 & 7 & 7 & 0 & 0 & 30 & 31 \\
$81-90$ & 3 & 3 & 6 & 6 & 2 & 2 & 1 & 1 & 12 & 12 \\
$>91$ & 0 & 0 & 0 & 0 & 0 & 0 & 1 & 1 & 1 & 1 \\
Total & 28 & 29 & 53 & 54 & 12 & 12 & 5 & 5 & 98 & 100 \\
\hline
\end{tabular}

Tabel 6. Distribusi bunyi clicking pada lansia dengan TMJ di Kecamatan Wanea

\begin{tabular}{ccc}
\hline Bunyi clicking & n & \% \\
\hline Ada & 70 & 71 \\
Tidak Ada & 28 & 29 \\
Total & 98 & 100 \\
\hline
\end{tabular}

Tabel 7. Distribusi Bunyi Clicking Berdasarkan Jenis Kelamin

\begin{tabular}{ccccccc}
\hline \multirow{2}{*}{ Jenis kelamin } & \multicolumn{2}{c}{ Ada bunyi clicking } & \multicolumn{2}{c}{ Tidak ada bunyi clicking } & \multicolumn{2}{c}{ Total } \\
\cline { 2 - 7 } & $\mathrm{n}$ & $\%$ & $\mathrm{n}$ & $\%$ & $\mathrm{n}$ & $\%$ \\
\hline $\mathrm{L}$ & 25 & 26 & 10 & 10 & 35 & 36 \\
$\mathrm{P}$ & 45 & 45 & 18 & 19 & 63 & 64 \\
Total & 70 & 71 & 28 & 29 & 98 & 100 \\
\hline
\end{tabular}

Tabel 8. Distribusi bunyi clicking berdasarkan usia

\begin{tabular}{ccccccc}
\hline \multirow{2}{*}{$\begin{array}{c}\text { Usia } \\
\text { (tahun) }\end{array}$} & \multicolumn{2}{c}{ Ada bunyi clicking } & \multicolumn{2}{c}{ Tidak ada bunyi clicking } & \multicolumn{2}{c}{ Total } \\
\cline { 2 - 7 } & $\mathrm{n}$ & $\%$ & $\mathrm{n}$ & $\%$ & $\mathrm{n}$ & $\%$ \\
\hline $60-70$ & 38 & 39 & 17 & 17 & 55 & 56 \\
$71-80$ & 22 & 22 & 8 & 8 & 30 & 31 \\
$81-90$ & 9 & 9 & 3 & 3 & 12 & 12 \\
$>91$ & 1 & 1 & 0 & 0 & 1 & 1 \\
Total & 70 & 71 & 28 & 29 & 98 & 100 \\
\hline
\end{tabular}


Gabrila, Tendean Zuliari: Gambaran temporomandibular disorders ...

Tabel 9. Distribusi bunyi clicking berdasarkan klasifikasi TMD

\begin{tabular}{ccccccc}
\hline \multirow{2}{*}{ Klasifikasi TMD } & \multicolumn{2}{c}{ Ada bunyi clicking } & \multicolumn{2}{c}{ Tidak ada bunyi clicking } & \multicolumn{2}{c}{ Total } \\
\cline { 2 - 7 } & $\mathrm{n}$ & $\%$ & $\mathrm{n}$ & $\%$ & $\mathrm{n}$ & $\%$ \\
\hline Tidak ada TMD & 0 & 0 & 28 & 29 & 28 & 29 \\
TMD ringan & 53 & 54 & 0 & 0 & 53 & 54 \\
TMD sedang & 12 & 12 & 0 & 0 & 12 & 12 \\
TMD berat & 5 & 5 & 0 & 0 & 5 & 5 \\
Total & 70 & 71 & 28 & 29 & 98 & 100 \\
\hline
\end{tabular}

Tabel 10. Distribusi kehilangan gigi pada lansia di Kecamatan Wanea

\begin{tabular}{llcccc}
\hline \multirow{2}{*}{ Kehilangan gigi } & \multicolumn{2}{c}{ RA } & \multicolumn{2}{c}{ RB } \\
\cline { 2 - 6 } & Klas I & 30 & 31 & 35 & $\%$ \\
\hline Klasifikasi kehilangan & Klas II & 23 & 23 & 16 & 16 \\
gigi menurut Kennedy & 25 & 26 & 18 & 18 \\
& Klas III & 0 & 0 & 9 & 9 \\
& Klas IV & 20 & 20 & 20 & 20 \\
& Seluruh gigi & 98 & 100 & 98 & 100 \\
\hline
\end{tabular}

\section{BAHASAN}

Penelitian yang dilakukan pada lansia di Kecamatan Wanea mendapatkan 98 responden dengan kategori jenis kelamin diperoleh perempuan $(64 \%)$ lebih dominan dari laki-laki. Hal ini dikarenakan lansia perempuan di Kecamatan Wanea lebih aktif dari pada laki-laki. Peneliti menemukan di lapangan bahwa laki-laki lebih banyak menolak untuk diwawancarai daripada perempuan. Penelitian ini sejalan dengan hasil penelitian Iswatin et al. ${ }^{5}$ dan Maqfirah $A$ et al. $^{3}$ yang mendapatkan responden lansia perempuan lebih dominan dari pada laki-laki.

Semakin lansia bertambah tua, semakin menurun pula kondisi fisik maupun psikologis yang mengakibatkan lansia lebih rentan terhadap penyakit. Pada penelitian ini paling banyak ditemukan interval umur 60-70 tahun sebanyak 55\% dan paling sedikit yaitu interval umur $>91$ tahun hanya 1\%. Hal ini dikarenakan lansia dengan interval usia 60-70 tahun umumnya masih dapat berkomunikasi dengan baik, beraktivitas normal dan kooperatif dibandingkan dengan yang berusia $>91$ tahun yang kondisi fisiknya semakin menurun. Penelitian inipun sejalan dengan penelitian yang dilakukan oleh Iswatin et al. ${ }^{5}$ yang mendapatkan lansia berusia 70 tahun dominan dalam penelitian tersebut.

Temporomandibular Disorers (TMD) pada lansia di Kecamatan Wanea diukur menggunakan Fonseca's Questionnaire yaitu kuesioner baku dari Foseca yang berasal dari Brazil. Hasil penelitian mengenai TMD pada lansia di Kecamatan Wanea menunjukkan $70 \quad(71 \%)$ lansia mengalami TMD dengan klasifikasi 53 (54\%) lansia mengalami TMD ringan, 12 (12\%) lansia mengalami TMD sedang, dan 5 (5\%) lansia mengalami TMD berat; 28 (29\%) lansia tidak mengalami TMD. Hasil penelitian TMD dengan penggolongan jenis kelamin, diperoleh hasil 10 (10\%) lansia laki-laki dan 18 (19\%) lansia perempuan yang tidak mengalami TMD. Terdapat $16(16 \%)$ lansia laki-laki dan 37 (38\%) lansia perempuan mengalami TMD ringan. Masing-masing $6(6 \%)$ lansia lakilaki dan perempuan mengalami TMD sedang dan $3(3 \%)$ lansia laki-laki dan 2 (2\%) lansia perempuan yang mengalami TMD berat.

Penelitian yang sama menggunakan Fonseca's Questionnaire untuk mengukur TMD pada lansia sudah pernah di lakukan di Indonesia yaitu oleh Maqhfirah $\mathrm{A}^{3}$ di panti jompo Tresna Werdha Gau Mabaji 
Kabupaten Gowa tahun 2010 dengan hasil kelompok umur 91-100 tahun memiliki prevalensi kelainan TMD yang paling berat yaitu 2\%, sedangkan kelompok umur 60-70 memiliki prevalensi kelainan TMD paling ringan sebanyak $18 \%$ dan perempuan lebih banyak mengalami TMD sebesar $58 \%$ dibandingkan jenis kelain laki-laki sebesar $42 \%$.

Hasil penelitian ini menunjukkan bahwa perempuan (64\%) lebih banyak mengalami TMD dibandingkan laki-laki. Hasil penelitian ini sejalan dengan penelitian yang dilakukan oleh Iswatin et al. $^{5}$ yang mendapatkan perempuan $(73,8 \%)$ lebih sering mengalami TMD. Penelitian yang dilakukan oleh Maqhfirah ${ }^{3}$. di Panti Jompo Tresna Werdha Gau Mabaji Kabupaten Gowa juga mendapatkan perempuan $(58 \%)$ lebih banyak mengalami TMD Penelitian yang dilakukan di luar negeri yaitu di Helsinki Finlandia tahun 2004 oleh Hiltunen ${ }^{7}$ pada 364 lansia (rentang usia 81-91 tahun) dengan hasil perempuan lebih sering mengalami gejala TMD dibandingkan laki-laki.

Penelitian yang dilakukan oleh Marpaung et al. ${ }^{8}$ dan Dewanti et al. ${ }^{9}$ melaporkan bunyi pada sendi temporomandibula sebagai gejala dan tanda yang paling sering ditemukan pada pasien dengan TMD. Hasil penelitian tersebut memiliki keterkaitan dengan penelitian ini dimana terdapat $71 \%$ responden yang memiliki bunyi clicking pada sendi temporomandibular. Bunyi clicking pada sendi temporomandibular ditemukan pada lansia yang mengalami TMD ringan, TMD sedang maupun TMD berat. Bunyi clicking di sendi temporomandibular pada penelitian ini paling banyak ditemukan pada lansia perempuan yaitu sebanyak 63 lansia (64\%). Hal ini serupa dengan hasil penelitian yang dilakukan oleh Adilah et al. ${ }^{10}$ di Jember yang menemukan bahwa jenis kelamin perempuan lebih rentan mengalami bunyi clicking di sendi temporomandibular dibandingkan laki-laki.

Perempuan umumnya lebih rentan terhadap penurunan kondisi fisik diawali dengan adanya perubahan hormon yang terjadi. Pada lanjut usia, perempuan telah mengalami menoupause dan seiring itu terjadi pula perubahan psikologis yang menyebabkan perempuan lebih mudah mengalami stres. Stres emosional dapat menyebabkan peningkatan aktifitas otot pada posisi istirahat yang dapat menimbulkan kelelahan dan spasme otot. Spasme otot yang terjadi akan meningkatkan respon saraf simpatis yang menyebabkan nyeri otot mastikasi. Menurut Moore, umumnya pada usia 35 tahun untuk perempuan dan usia 45 tahun untuk laki-laki massa tulang mencapai maksimum. Setelah titik itu, lebih banyak massa tulang yang hilang daripada yang dibentuk sehingga perempuan cenderung mengalami osteoporosis. Hal tersebut menjelaskan mengapa lansia perempuan lebih sering mengalami TMD dan bunyi clicking dibandingkan lansia laki-laki. ${ }^{3,12}$

Kehilangan gigi khususnya di bagian oklusal sering diindikasikan sebagai penyebab TMD karena adanya kelainan oklusal. Pada penelitian ini ditemukan 78 lansia (79\%) mengalami kehilangan gigi sebagian dan 20 lansia (20\%) mengalami kehilangan gigi seluruhnya serta tidak ada lansia yang tidak memiliki kehilangan gigi. Penelitian ini juga menemukan kehilangan gigi paling banyak terdapat di RB Klas I Kennedy, yaitu kehilangan gigi dibagian posterior bilateral.

Penelitian ini berkaitan dengan penelitian oleh Ribka ${ }^{11}$ yang melaporkan adanya hubungan kehilangan gigi dengan TMD berdasarkan jumlah kuadran kehilangan gigi posterior, dukungan oklusal, dan jumlah kehilangan gigi serta terdapat peningkatan insiden TMD seiring dengan peningkatan jumlah kehilangan gigi. Hal yang sering terjadi pada seseorang dnegan kehilangan gigi posterior ialah terdapatnya perbedaan posisi salah satu atau kedua processus condylaris sendi temporomandibular ketika beroklusi. Caput processus condylaris bisa mengalami penekanan terlalu keras terhadap fossa glenoidalis dan menyebabkan kartilago discus articularis rusak yang akan menarik ligamen terlalu kuat sehingga 
menyebabkan gangguan pada kedua sendi rahang. ${ }^{13}$

\section{SIMPULAN}

Berdasarkan hasil penelitian terhadap lansia di kecamatan Wanea dapat disimpulkan bahwa sebagian besar lansia mengalami TMD. Kelompok usia 60-70 tahun, jenis kelamin perempuan, dan klasifikasi TMD ringan yang paling sering ditemukan.

\section{SARAN}

Perlu adanya peningkatan pengetahuan pada masyarakat termasuk para lansia tentang kesehatan gigi dan mulut terutama mengenai temporo-mandibular disorders.

\section{DAFTAR PUSTAKA}

1. Kementerian Kesehatan RI. Buletin Jendela dan Data Informasi Kesehatan. Jakarta. Semester I. 2013

2. Hanna S, Andar I. Memahami Krisis Lanjut Usia: Uraian Medis dan Pedagosis Pastoral. Jakarta: Gunung Mulia, 2009

3. Maqhfirah A. Prevalensi Kelainan Sendi Temporomandibular pada Lanjut Usia di Panti Jompo Tresna Werdah Gau Mabaji Kabupaten Gowa [Skripsi]. Makassar: Universitas Hasanuddin. 2010

4. Ulpa JR, Priyanto D, Benyamin B. Hubungan kehilangan gigi posterior bilateral free end terhadap timbulmya clicking pada sendi temporomandibular. Medali Jurnal. 2015;2(1):14-17.

5. Khasanah AIKL, Priyanto D. Pengaruh gangguan sendi temporomandibula terhadap kualitas hidup terkait kesehatan gigi dan mulut pada lansia. Jurnal PDGI. 2012;61(3):102-9.

6. Himawan LS, Kusdhany LS, Ariani N.
Tempromandibular disorders in elderly patients. Med J Indones. 2007;16(4):237-9.

7. Hiltunen K. Temporomandibular disorders in the elderly: A 5 year follow-up of signs and symptoms of TMD [Dissertation]. Finlandia: University of Helsinki; 2004.

8. Marpaung C, Himawan LS, Roemoso FG, Rahardjo TBW. Hubungan antara tingkat keparahan gangguan sendi temporomandibula dan perbedaan karakteristik bunyi sendi temporomandibula.

JKGUL. 2003;10(Edisi Khusus); 644-51.

9. Dewanti L, Kurnikasari E, Rikmasari R. Prevalence of severity degrees of temporomandibular joint disorder based on sex and age group. Padjadjaran Journal of Dentistry.. 2003; 1:14-24.

10.Adilah D. Hubungan antara kehilangan gigi posterior dengan kliking sendi temporomandibular berdasarkan jenis kelamin di Klinik Prostodonsia RSGM Universitas Jember [Skripsi]. Jember: Fakultas Kedokteran Gigi Universitas Jember; 2015.

11.Ribka S. Hubungan kehilangan gigi sebagian terhadap gangguan sendi temporomandibula pada pasien RSGMP FKG USU [Skripsi]. Medan: Fakultas Kedokteran Gigi Universitas Sumatera Utara; 2015.

12.Najma S, Cholil, Bayu IS. Deskripsi kasus temporomandibular disorders pada pasien di RSUD Ulin Banjarmasin bulan Juni - Agustus 2013 Tinjauan berdasarkan jenis kelamin, etiologi dan klasifikasi. Dentino. 2014;II(1):70-3.

13. Suryonegoro H. Pencitraan of temporomandibular disorders. Jurnal PDGI. 2005;55(Edisi khusus):182. 